This is an electronic reprint of the original article. This reprint may differ from the original in pagination and typographic detail.

Author(s): Böckerman, Petri; Hyytinen, Ari; Maczulskij, Terhi

Title: Devil in disguise : does drinking lead to a disability pension?

Year: $\quad 2016$

Version:

Please cite the original version:

Böckerman, P., Hyytinen, A., \& Maczulskij, T. (2016). Devil in disguise : does drinking lead to a disability pension?. Preventive Medicine, 86, 130-135. https://doi.org/10.1016/j.ypmed.2016.03.008

All material supplied via JYX is protected by copyright and other intellectual property rights, and duplication or sale of all or part of any of the repository collections is not permitted, except that material may be duplicated by you for your research use or educational purposes in electronic or print form. You must obtain permission for any other use. Electronic or print copies may not be offered, whether for sale or otherwise to anyone who is not an authorised user. 


\section{Accepted Manuscript}

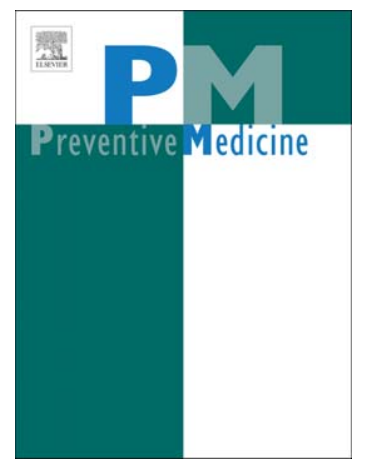

DOI:

Reference:

doi: 10.1016/j.ypmed.2016.03.008

YPMED 4574

To appear in: $\quad$ Preventive Medicine

Received date: 20 October 2015

Revised date: $\quad 29$ February 2016

Accepted date: $\quad 7$ March 2016

Please cite this article as: Böckerman Petri, Hyytinen Ari, Maczulskij Terhi, Devil in disguise: Does drinking lead to a disability pension?, Preventive Medicine (2016), doi: 10.1016/j.ypmed.2016.03.008

This is a PDF file of an unedited manuscript that has been accepted for publication. As a service to our customers we are providing this early version of the manuscript. The manuscript will undergo copyediting, typesetting, and review of the resulting proof before it is published in its final form. Please note that during the production process errors may be discovered which could affect the content, and all legal disclaimers that apply to the journal pertain. 


\section{Devil in disguise: does drinking lead to a disability pension?}

\section{Petri Böckerman ${ }^{1}$, Ari Hyytinen ${ }^{2}$ and Terhi Maczulskij ${ }^{3}$}

${ }^{1}$ Corresponding author. Turku School of Economics, Labour Institute for Economic Research and IZA. Address: Pitkänsillanranta 3A, FI-00530 Helsinki, Finland. Phone: +358-9-2535 7330. Fax: +358-9-2535 7332. E-mail: petri.bockerman@ labour.fi

${ }^{2}$ University of Jyväskylä, School of Business and Economics, Jyväskylä, Finland. E-mail: ari.t.hyytinen@jyu.fi

${ }^{3}$ Labour Institute for Economic Research, Helsinki, Finland. E-mail: terhi.maczulskij@labour.fi

$* * *$

The authors declare that there are no conflicts of interest.

$* * *$

Word count, abstract: 181

Word count, article: 3498 


\title{
Devil in disguise: does drinking lead to a disability pension?
}

\begin{abstract}
Objectives. To examine whether alcohol consumption in adulthood is related to the incidence of receiving a disability pension later in life.

Methods. Twin data for Finnish men and women born before 1958 were matched to registerbased individual information on disability pensions. Twin differences were used to eliminate both shared environmental and genetic factors. The quantity of alcohol consumption was measured as the weekly average consumption using self-reported data from three surveys (1975, 1981 and 1990). The disability pension data were evaluated from 1990-2004.

Results. The models that account for shared environmental and genetic factors reveal that heavy drinkers are significantly more likely to receive a disability pension than moderate drinkers or constant abstainers. Heavy drinking that leads to passing out is also positively related to receiving a disability pension. The results were robust to the use of potential confounders that twins do not share, such as education years, the number of chronic diseases, physical activity at work and leisure, and stressful life events. Conclusion. Drinking profiles in early adulthood are an important predictor of receiving a disability pension later in life.
\end{abstract}

Keywords Alcohol consumption, disability pension, co-twin control, twins 


\section{Introduction}

Does heavy drinking in early adulthood predict the incidence of receiving a disability pension? There are two policy motivations to examine this question. First, heavy drinking is a potentially important determinant of health and labor market transitions. Second, understanding the link between alcohol consumption and receiving a disability pension is a policy-relevant issue because the labor force of industrialized countries is ageing rapidly (OECD, 2006). Keeping public expenditures in control and maintaining the labor supply at a sufficient level calls for longer working careers. Alcohol consumption is a modifiable risk factor that can be affected by regulating the price and the availability of alcohol. For this reason, it is a potential policy instrument that can have an impact on labor market attachment and the length of working careers.

The literature has linked drinking profiles to the incidence of receiving a disability pension. Swedish research suggests that alcohol use is positively associated with receiving a disability pension (Ropponen et al., 2011; Sidorchuk et al., 2012; Upmark et al., 1997), whereas a Finnish study did not find such an association (Krause et al., 1997). There is also evidence of a U-shaped relationship between alcohol consumption and disability retirement. Thus, alcohol misuse, as well as teetotalism, are both positively related to receiving a disability pension (Månssaon et al., 1999; Skogen et al., 2011; Salonsalmi et al., 2012; Upmark et al., 1999). Among abstainers, former drinkers are more likely to receive disability pensions than constant abstainers (Skogen et al., 2011).

We contribute to the literature by using a large and representative dataset on twins. Having within twin-pair variation is useful if there are unobservable factors that are correlated with both alcohol consumption and disability, leading to a (spurious) correlation between the outcome and the predictor of interest. First, using data on non-identical (dizygotic, DZ) twins 
allows us to account for shared family and neighborhood factors as well as for other sibling effects, such as similar friends and social network. Family members and various peer groups, such as close friends and roommates, are a significant determinant of alcohol consumption (e.g., Brooks-Russell et al., 2014; Guo et al., 2015; Poelen et al., 2007). Second, using data on identical (monozygotic, MZ) twins allows us to also account for inherited traits and preferences that may affect risk-taking behaviors (van Dongen et al., 2012). Because genetic endowment is a contributor to many chronic diseases and thus disability and because alcohol consumption has a significant heritable component (Van Eerdewegh et al., 1998), it is important to account for its effect on the incidence of receiving a disability pension. Furthermore, there is evidence that exposure to peers who use alcohol is influenced by genetic factors (e.g., Fowler et al., 2007; Guo et al., 2015). With the use of MZ twins we are thus able to account for individual differences in vulnerability to peer effects.

Only three empirical studies have used twin data to estimate how alcohol consumption is related to the incidence of receiving a disability pension (Korhonen et al., 2015; Ropponen et al., 2011; Samuelsson et al., 2013). Using Swedish twin survey data, Ropponen et al. (2011) examine the effect of drinking on the incidence of receiving a disability pension for DZ pairs. This analysis does not allow for confounding caused by genetic factors. A significant positive relationship between drinking and receiving a disability pension was found in some specifications. In another analysis that uses the same Swedish twin data, both teetotalism and alcohol misuse elevate the risk of receiving a disability pension when shared family and neighborhood factors are accounted for (Samuelsson et al., 2013). However, these patterns become statistically insignificant when genetic factors are also controlled for by using within MZ-pair variation. Korhonen et al. (2015) used the Finnish twin and register data (like we do) to study the incidence of receiving a disability pension and its relation to past drinking and smoking. The authors find that the two are independent predictors of disability 
retirement and, in particular, that both teetotalism and excess alcohol use predict disability retirement. However, the estimations that include the alcohol use categories account neither for the effects of a shared family environment nor for genetics.

Our study extends the literature in three important policy-relevant ways. First, we base our estimates on conditional (fixed-effects) logistic regression that allows us to account for the factors that two twins share. Thus, our preferred results are estimated for a sample of MZs. Accounting for both family environment and genetics brings us closer to establishing an unconfounded (causal) effect because many potential confounders such as risk-taking behaviors are related to genetics. This is an important extension, because evidence-based public health policy should be guided by causal reasoning and because only one prior study has utilized within-twin dimension (Samuelsson et al., 2013). Second, in contrast to the earlier studies based on twins our analysis uses a longitudinal research design to distinguish former drinkers from constant abstainers. We accomplish this by using detailed information on alcohol consumption that the three twin surveys provide us with. Therefore, our study is the first to address the open question of whether the incidence of receiving a disability pension among abstainers is heterogeneous in terms of their drinking history even after accounting for both shared family and genetic factors. This extension is important, because the potential heterogeneity matters for individuals' choices and policy. Third, we assess whether the relationship is robust after accounting for a very rich set of confounders that twins do not share such as the number of chronic diseases, physical activity at work and leisure, and stressful life events. 


\section{Institutional setting}

Disability pensions can be granted to 16-64-year-old individuals who have become permanently incapable of working in Finland. If the disability has lasted continuously for at least one year, the individual is entitled to apply for a disability pension, either in the form of a rehabilitation subsidy or a (permanent) disability pension. Individuals who are temporarily incapable of working and whose handicaps or illnesses are expected to improve through rehabilitation are normally granted the rehabilitation subsidy. According to the statistics compiled by the Finnish Centre of Pensions, over 50\% of applicants are granted the permanent disability pension, and the rest are granted the rehabilitation subsidy. Approximately $80 \%$ of the rehabilitation benefits are eventually converted into disability pensions.

\section{Methods}

\section{Data sources and the sample}

Our twin data source is the Older Finnish Twin Cohort Study (of the Department of Public Health in the University of Helsinki); see Kaprio et al. (1979). The data were originally compiled from the Central Population Registry of Finland, for which the initial twin candidates were persons with the same birth date, commune of birth, sex, surname at birth and were born before 1958. Three surveys were conducted in 1975, 1981 and 1990. The response rate for the latest survey was $77 \%$, totaling 12,502 twin pairs. The attrition and representativeness of the twin sample have been documented previously (e.g., Hyytinen et al., 2013; Kaprio et al., 1979; Maczulskij, 2013). 
Following Hyytinen et al. (2013), we linked the twin data to the Finnish Longitudinal Employer-Employee Data (FLEED) using personal identifiers. FLEED is an annual panel and is based on administrative registers that are collected by Statistics Finland. In the data, $16 \%$ of individuals were granted a disability pension at some point in the observation window from 1990-2004.

Our analysis focuses on twin pairs for whom we have data on alcohol consumption, other covariates and disability pension. We restrict all analyses to the cohort of twins who are less than 65 years old in 2004. After further excluding observations with missing data for the other sibling, the number of twin pairs decreased to 5,903 (i.e., 11,806 individuals). The total number of person-year observations in the data is 151,100 .

Our dependent variable takes the value of one for those person-year observations when a person receives a disability pension (or has the status of individual early retirement) and is zero otherwise. Some of the individuals who initially obtain a rehabilitation benefit may return to work. Once an individual with a disability pension begins to obtain either an old-age or unemployment pension, his/her subsequent person-year observations are not included in the sample.

\section{Drinking profiles}

The quantity of alcohol consumed is measured as the daily average consumption as documented by Kaprio et al. (1987) (see also Böckerman et al. 2015). The initial measure is the self-reported amount of alcohol consumed in 1975, 1981 and 1990. The twin survey gathered information on the frequency of alcohol consumption, measured by daily consumption per month, using a five-point scale ( 1 = 'never', 5 = 'over 16 days a month') and separately for different types of alcohol: beer, wine and spirits. The quantities were measured 
on a seven-point scale for each alcohol type, with the upper limits for consumption of more than 48 bottles of beer ( 10 bottles of wine) per week or more than 20 bottles of spirits per month. A unit of alcohol is defined as 12 grams of pure alcohol. Using this information, alcohol consumption was initially converted into grams of pure alcohol consumed daily in each twin survey. We have further converted alcohol use in grams to average weekly consumption.

In Finland, 280 grams of pure alcohol per week (i.e., $\approx 24$ units of alcohol) is commonly used as the limit for heavy drinking for men, and 190 grams per week (i.e., $\approx 16$ units of alcohol) is the limit for heavy drinking for women (Aalto, 2001). Using these thresholds, we assign the individuals into four mutually exclusively categories (see also Table 1): Former drinkers (those who were classified as abstainers in 1990, but did consume alcohol in 1975 or/and 1981); Constant abstainers (those who were classified as abstainers in 1975, 1981 and 1990); Moderate drinkers (those who consumed alcohol in 1990 but less than 280 (190) grams per week); and Heavy drinkers (those who consumed alcohol in 1990 at a rate of more than 280 (190) grams per week).

The twin data also contain a self-reported measure for pass out frequency (i.e., losing consciousness due to intoxication caused by alcohol drinking). It is based on the question about the pass out frequency during the past 12 months in the 1990 twin survey. Thus, we use it as an indicator variable that obtains the value of one if the pass out frequency was positive (and zero otherwise).

\section{Statistical methods}

We estimate models for the likelihood of a person being on a disability pension over the period 1990-2004. First, we consider the data as individuals and use a standard logistic 
regression to relate the drinking profiles to disability pensions for a combined sample of DZ and MZ twins (see, e.g., Krause et al., 1997; Upmark et al., 1999). Second, we performed a conditional (fixed-effects) logistic regression that allows us to account for those factors that two twins share (e.g., Chamberlain, 1980). The specification for the DZ twin pairs accounts for shared family and environmental factors, including the overall macroeconomic situation (e.g., the phase of the business cycle). The estimation also controls fully for age and cohort effects, even if they had a complex non-linear effect on the incidence of receiving a disability pension. Our preferred specification uses the sample of $\mathrm{MZ}$ twin pairs for whom it is possible to eliminate both shared environmental and genetic factors.

\section{Covariates}

The baseline specifications do not include covariates because they may not be predetermined with respect to alcohol consumption. In additional models, we account for socioeconomic characteristics and health-related factors, as well as the measures of physical activity and mental stability, physical working conditions and past experiences of stressful life events. These variables may contribute to the likelihood of receiving a disability pension and may also be correlated with alcohol consumption. For example, physical activity is associated with labor market outcomes (Hyytinen and Lahtonen, 2013).

The socioeconomic confounders include education (measured in years, based on the highest completed education level) and marital status (= 1 if ever married, as reported from the 1975,1981 and 1990 twin surveys). The health-related covariates include the number of chronic diseases and smoking. The number of chronic diseases (1981) is used to account for initial differences in health. The twin data contain information in total on 18 chronic diseases in 1981. The most important of these are emphysema, chronic obstructive pulmonary disease, 
high blood pressure, angina pectoris, peptic ulcer, diabetes, and gout. Smoking is included to account for the effects of joint use of alcohol and cigarettes (Korhonen et al., 2015) and is measured using pack-years in 1990 (see, e.g., Böckerman et al., 2015).

Our measures of physical activity and mental stability refer to leisure time physical activity and indicators of neuroticism and extraversion. Leisure time physical activity was measured using the MET index (Metabolic Equivalent Tasks) (Ainsworth et al., 2000). Those scoring higher than 14 on the MET index were classified as active, and all others were classified as inactive. Neuroticism and extraversion and alcohol consumption are positively correlated (Martin and Sher, 1994; Raynor and Levine, 2009). Neuroticism (extraversion) was assessed by 10 (9) items in the short form of the Eysenck Personality Inventory in 1981 (Eysenck and Eysenck, 1975; Rose et al., 2008). Physical working conditions were measured with retrospective information on physically demanding work using self-reported information from all three surveys.

We also include a stressful life events (SLE) index from 1981 that is a weighted sum of 11 negative life shocks selected from the 17 Holmes and Rahe items. The shocks include e.g. loss of a job, divorce or separation and death of a spouse (for details, see Riese et al., 2013). Stressful life events may cause one twin to consume alcohol and also contribute to his/her early retirement in the form of a disability pension.

\section{Results}

Descriptive evidence

$59 \%$ of individuals are classified as moderate drinkers (Table 2). The proportion of former drinkers and constant abstainers is $5 \%$. The share of heavy drinkers $(31 \%)$ is relatively high, 
compared to Böckerman et al. (2015), who however exclude the retired (incl. disability pension), or to Korhonen et al. (2015). Had we used Korhonen's et al. (2015) definition for heavy use, the share in our sample from the 1975 survey would match theirs and the share calculated from the 1990 survey would somewhat exceed the share this paper reports. The increase is thus due to a peak in alcohol consumption in 1990 and the age structure of our sample. This feature is also reflected in the pass out frequency $(37 \%)$.

Persons who are classified as heavy drinkers, constant abstainers or former drinkers or who have experienced passing out due to drinking are more likely to receive a disability pension compared to moderate drinkers. The null hypothesis of equal group means is rejected for both drinking measures.

\section{Estimates}

We estimated our logistic regressions separately for the categorical measures of alcohol consumption (Table 3, Panel A) and our measure of pass out frequency (Table 3, Panel B). The estimations for the total twin sample (Column 1) account for gender and age to be more comparable to the specifications (Columns 2-4) that are estimated using the conditional (fixed-effects) logistic regression that control for such invariant factors within twin-pair variables.

The logistic regression estimates reveal a U-shaped relationship between alcohol consumption and the incidence of receiving a disability pension (Table 3, Panel A): relative to the moderate drinkers, former drinkers $(\mathrm{OR}=2.289, \mathrm{p}<0.001)$ and constant abstainers $(\mathrm{OR}=$ $2.675, \mathrm{p}<0.001)$ are more likely to receive a disability pension. The odds ratio is smallest for heavy drinkers $(\mathrm{OR}=1.403, \mathrm{p}<0.001)$. We also find (Table 3, Panel B) that passing out due to drinking is positively related to the incidence of receiving a disability pension $(\mathrm{OR}=1.375$, 
$\mathrm{p}<0.001)$. These results do not change dramatically when we use the estimation method that accounts for shared environments (Columns 2 and 3).

In the preferred specification, we use the smaller sample of $\mathrm{MZ}$ twin pairs to account for both shared family and neighborhood factors and genetic factors (Column 4). Being a heavy drinker is significantly positively associated with the incidence of receiving a disability pension $(\mathrm{OR}=1.790, \mathrm{p}=0.025)$. For former drinkers, the relationship is no longer statistically significant at the $5 \%$ significance level $(\mathrm{OR}=2.125, \mathrm{p}=0.061)$, even though the size of the OR is larger than that for heavy drinkers. However, the OR estimates for former and heavy drinkers are, in each column, jointly significant (in our preferred specification for MZ twin pairs: F-test $=7.41, \mathrm{p}$-value $=0.025$ ).

The association between passing out due to drinking and disability retirement is also positive and significant in the preferred specification for $\mathrm{MZ}$ twin pairs $(\mathrm{OR}=1.576, \mathrm{p}=$ 0.034). When we add the indicator for passing out to the models together with the categorical alcohol consumption measures (not reported), the ORs for heavy drinkers become statistically insignificant. This finding is not surprising, because heavy drinking and passing out reflect similar (adverse) drinking behaviors. Heavy drinking commonly leads to passing out. The pairwise correlation between these two variables is $0.776(\mathrm{p}<0.001)$. The OR estimates for passing out and heavy drinkers are also jointly significant (results not reported; in our preferred specification for MZ twin pairs: F-test $=6.09$, p-value $=0.048$ ).

Next, we augment our preferred model for MZs with the covariates that account for potential non-shared confounders using conditional (fixed-effects) logistic regression (Table 4). The most important observation is that the estimate for heavy drinkers remains basically intact $(\mathrm{OR}=1.866, \mathrm{p}=0.025)$. Similarly, the OR estimates for former and heavy drinkers are, as in Table 3, jointly significant $(\mathrm{F}$-test $=7.10, \mathrm{p}$-value $=0.029)$. Education years are negatively associated with disability pension $(\mathrm{OR}=0.832, \mathrm{p}=0.002)$. In contrast, the number 
of different chronic diseases is positively associated with receiving a disability pension $(\mathrm{OR}=$ 1.207, $\mathrm{p}=0.038$ ). Because alcohol consumption is a risk factor for some chronic diseases, we have checked the robustness of the results in Table 4 by excluding the variable that captures the number of chronic diseases from the set of explanatory variables (not reported). The result for heavy drinkers remains intact $(\mathrm{OR}=1.724, \mathrm{p}=0.045)$. The estimate for former drinkers is again larger in size, but is not statistically significant $(\mathrm{OR}=1.910, \mathrm{p}=0.113)$.

\section{Discussion}

This paper used twin data linked to register-based information on an individuals' labor market status to examine the relationship between alcohol consumption and the incidence of receiving a disability pension. We contributed to the literature in three major ways. First, we used conditional (fixed-effects) logistic regression and a large and representative twin data to account for confounders related to both shared family and genetic factors. Second, using a longitudinal research design we distinguished former drinkers from constant abstainers. Third, we accounted for an unusually rich set of potential confounders that twins do not share.

The most important finding is that heavy drinkers are significantly more likely to receive a disability pension than moderate drinkers, even after accounting for shared family (peer) and genetic factors. The results are robust to the use of potential confounders that twins do not share, such as education years, differences in the number of chronic diseases, physical activity in leisure time and work, and stressful life events. Passing out due to drinking is also positively related to receiving a disability pension. We do not claim that the documented associations are necessarily causal effects. It is possible, for example, that a confounding psychological factor, which distinguishes two identical twins and which our observed covariates do not properly capture, may induce one twin to drink heavily early in life and also 
to retire earlier. However, the twin design allows us to establish that the associations are not induced by shared family environment or genetics.

Our data come from Finland, where alcohol consumption is a major and increasing health burden. Receiving a disability pension is the most common way to retire before the official retirement age in Finland. More than $20 \%$ of retiring Finns end up receiving a disability pension (OECD, 2014). While we have no strong reasons to doubt the external validity of our findings, it is prudent to note that the Finnish institutional environment and conditions for receiving a disability pension may be somewhat country-specific.

Our findings are highly policy-relevant for two reasons. First, early retirement in the form of a disability pension contributes to the fiscal burden of ageing nations. Promoting the labor market attachment of elderly persons alleviates the negative consequences of the demographic transition for the labor supply and supports the sustainability of the pension system. Heavy drinkers may warrant special attention in this regard. Second, the impact of alcohol consumption on the length of one's working career should be taken into account in the cost-benefit calculations that guide the optimal regulation of the availability and price of alcohol. According to our findings, moderate drinkers are the least likely to withdraw from the labor market early.

\section{Acknowledgements}

This research has been financially supported by the Jenny and Antti Wihuri Foundation. We would like to thank Jaakko Kaprio for access to the twin data. 


\section{References}

Aalto, M., 2001. Prevalence and Brief Intervention of Heavy Drinkers in Primary Health Care: Lahti Project Study. Tampere: Acta Universitatis Tamperensis 802.

Ainsworth, B.E., Haskell, W.L., Whitt, M.C., et al., 2000. Compendium of physical activities: an update of activity codes and MET intensities. Med Sci Sports Exerc 32, S498-S504.

Brooks-Russell, A., Simons-Morton, B., Haynie, D., et al., 2014. Longitudinal relationship between drinking with peers, descriptive norms, and adolescent alcohol use. Prev Sci 15, 497-505.

Böckerman, P., Hyytinen, A., Kaprio, J., 2015. Smoking and long-term labour market outcomes. Tob Control 24, 348-353.

Böckerman, P., Hyytinen, A., Maczulskij, T., 2015. Alcohol consumption and long-term labor market outcomes. Health Econ, DOI: 10.1002/hec.3290

Chamberlain, G., 1980. Analysis of covariance with qualitative data. Rev Econ Stat 47, 225238.

van Dongen, J., Slagboom, P.E, Draisma, H.H., et al., 2012. The continuing value of twin studies in the omics era. Nat Rev Genet 13, 640-653. 
Van Eerdewegh, P., Foroud, T., Hesselbrock, V., et al., 1998. Genome-wide search for genes affecting the risk for alcohol dependence. Am J Med Genet 81, 207-215.

Eysenck, H.J., Eysenck, S.B.G., 1975. Manual of the Eysenck Personality Questionnaire. London: Hodder and Stoughton.

Fowler, T., Shelton, K., Lifford, K., et al., 2007. Genetic and environmental influences on the relationship between peer alcohol use and own alcohol use in adolescents. Addiction 102, 894-903.

Guo, G., Li, Y., Wang, H., et al., 2015. Peer influence, genetic propensity, and binge drinking: a natural experiment and a replication. Am J Sociol 121, 914-954.

Hyytinen, A., Ilmakunnas, P., Toivanen, O., 2013. The return-to-entrepreneurship puzzle. Lab Econ 20, 57-67.

Hyytinen, A., Lahtonen, J., 2013. The effect of physical activity on long-term income. Soc Sci Med 96, 129-137.

Kaprio, J., Artimo, M., Sarna, S., et al., 1979. The Finnish Twin Registry: Baseline Characteristics. Section I: Materials, Methods, Representativeness and Results for Variables Special to Twin Studies. Helsinki: Department of Public Health, Publications, M(47). 
Kaprio, J., Koskenvuo, M., Langinvainio, H., et al., 1987. Genetic influences on use and abuse of alcohol: a study of 5638 adult Finnish twin brothers. Alcohol Clin Exp Res 11, 349356.

Korhonen, T., Smeds, E., Silventoinen, K., et al., 2015. Cigarette smoking and alcohol use as predictors of disability retirement: a population-based cohort study. Drug Alcohol Depend $155,260-266$.

Krause, N., Lynch, J., Kaplan, G.A., et al., 1997. Predictors of disability retirement. Scand J Work Environ Health 23, 403-143.

Maczulskij, T., 2013. Employment sector and pay gaps: genetic and environmental influences. Lab Econ 23, 89-96.

Martin, E., Sher, K., 1994. Family history of alcoholism, alcohol use disorders and the fivefactor model of personality. J Stud Alcohol Drugs 55, 81-90.

Månssaon, N.-O., Råstam, L., Eriksson, K.F., et al., 1999. Alcohol consumption and disability pension among middle-aged men. Ann Epidemiol 9, 341-348.

OECD, 2006. Live Longer, Work Longer. Paris: OECD.

OECD, 2014. Economic Surveys 2014. Paris: OECD. 
Poelen, E., Scholte, R., Williemsen, G., et al., 2007. Drinking by parents, siblings, and friends as predictors of regular alcohol use in adolescents and young adults: a longitudinal twinfamily study. Alcohol Alcohol 42, 362-369.

Raynor, D., Levine, H., 2009. Associations between the five-factor model of personality and health behaviors among college students. J Am Coll Health 58, 73-82.

Riese, H., Snieder, H., Jeronimus, B., et al., 2013. Timing of stressful life-events affects stability and change of neuroticism. Eur J Personality 28, 193-200.

Ropponen, A., Narusyte, J., Alexanderson, K., et al., 2011. Stability and change in health behaviours as predictors for disability pension: a prospective cohort study of Swedish twins. BMC Public Health 11:678.

Rose, R.J., Koskenvuo, M., Kaprio, J., et al., 1988. Shared genes, shared experiences, and similarity of personality: data from 14,288 adult Finnish co-twins. Pers Soc Psychol 54, $161-71$.

Salonsalmi, A., Laaksonen, M., Lahelma, E., et al., 2012. Drinking habits and disability retirement. Addiction 107, 2128-2136.

Samuelsson, Å., Ropponen, A., Alexanderson, K., et al., 2013. A prospective cohort study of disability pension due to mental diagnoses: the importance of health factors and behaviors. BMC Public Health 13:621. 
Sidorchuk, A., Hemmingsson, T., Romelsjö, A., et al., 2012. Alcohol use in adolescence and risk of disability pension: a 39 year follow-up of a population-based conscription survey. PLoS ONE 7:8.

Skogen, J., Knudsen, A., Mykletun, A., et al., 2011. Alcohol consumption, problem drinking, abstention and disability pension award. The Nord-Trøndelag Health Study (HUNT). Addiction 107, 98-108.

Upmark, M., Hemmingsson, T., Romelsjö, A., et al., 1997. Predictors of disability pension among young men: the role of alcohol and psychosocial factors. Eur J of Public Health 7, 20-28.

Upmark, M., Möller, J., Romelsjö, A., 1999. Longitudinal, population-based study of selfreported alcohol habits, high levels of sickness absence, and disability pension. J Epidemiol Community Health 53, 223-229. 
Table 1 Alcohol measures and their definitions

\begin{tabular}{|c|c|}
\hline Variable & Definition \\
\hline \multicolumn{2}{|l|}{ A: Drinking profile ${ }^{a}$} \\
\hline Former drinker & Abstainer in 1990, but did consume alcohol in 1975 or/and 1981 \\
\hline Constant abstainer & Abstainer in 1990, 1981 and 1975 \\
\hline Moderate drinker & $\begin{array}{l}\text { Consumed alcohol in 1990, but less than } 280 \text { ( } 190 \text { for women) } \\
\text { grams per week }\end{array}$ \\
\hline Heavy drinker & $\begin{array}{l}\text { Consumed alcohol in 1990, but more than } 280 \text { ( } 190 \text { for women) } \\
\text { grams per week }\end{array}$ \\
\hline \multicolumn{2}{|l|}{ B: Passing out } \\
\hline Passing out due to drinking & $\begin{array}{l}\text { Passed out due to excessive alcohol consumption during the } 12 \\
\text { months in } 1990\end{array}$ \\
\hline
\end{tabular}

${ }^{a}$ : Alcohol consumption is measured by weekly average consumption in grams of pure alcohol 
Table 2 Drinking profiles and disability pension

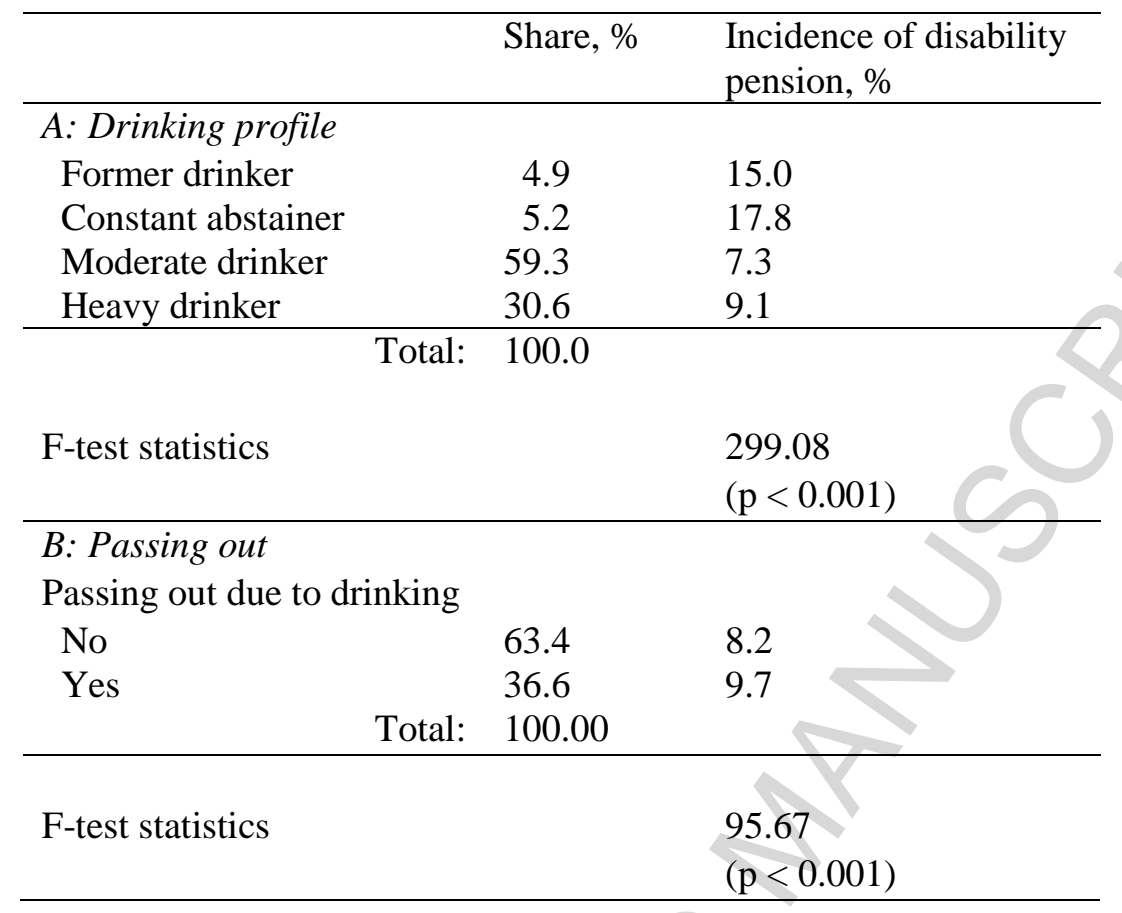

The shares in column 1 refer to year 1990. The percentages in column 2 are calculated from person-year observations 1990-2004. Heteroscedasticity-robust F-test statistics for the null hypothesis of equal group means. 
Table 3 Odds ratios (OR) from the models that predict disability pension by using alcohol consumption. Bivariate regressions

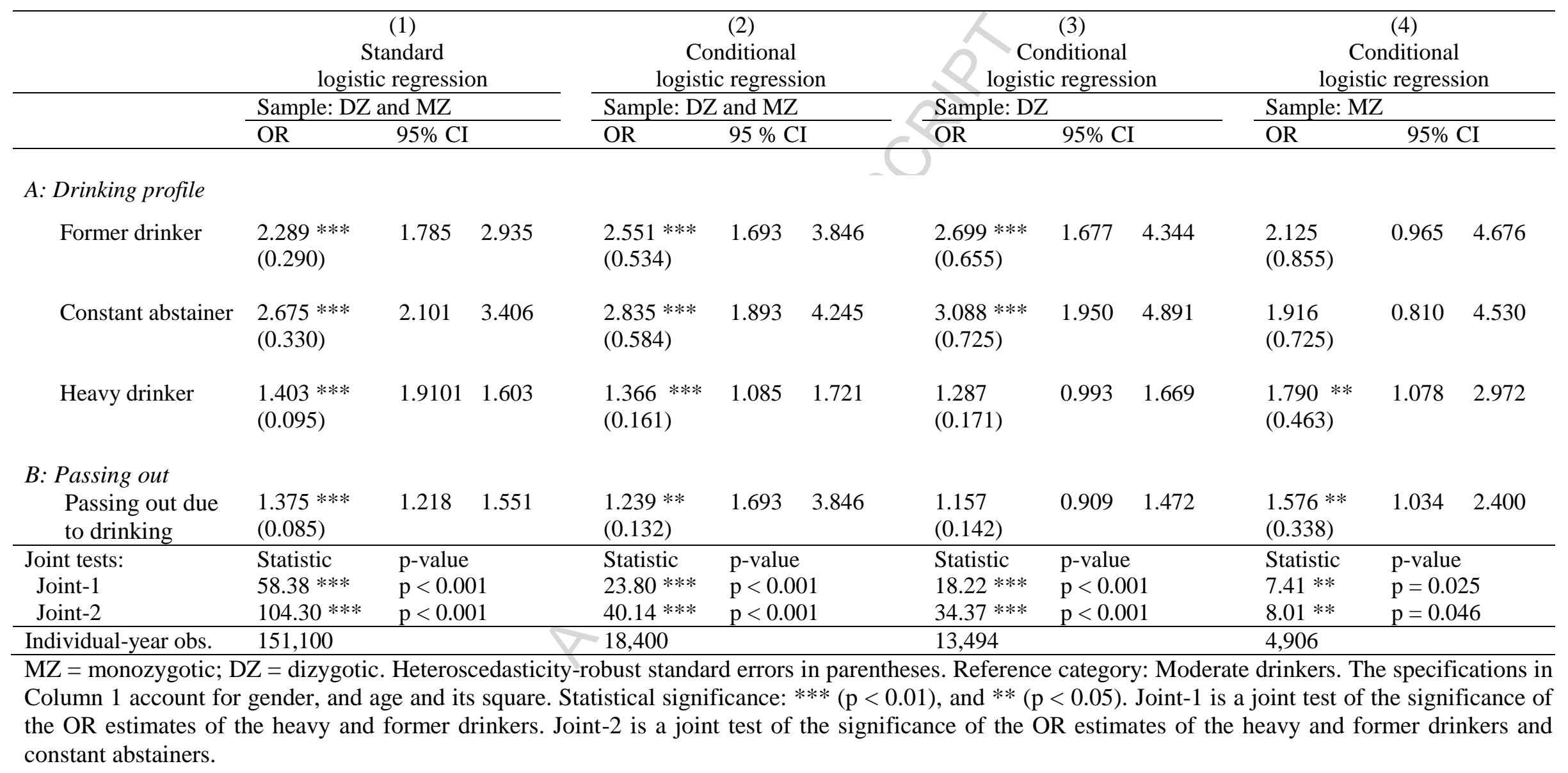


Table 4 Odds ratios (OR) from the models that predict disability pension by using alcohol consumption with additional covariates.

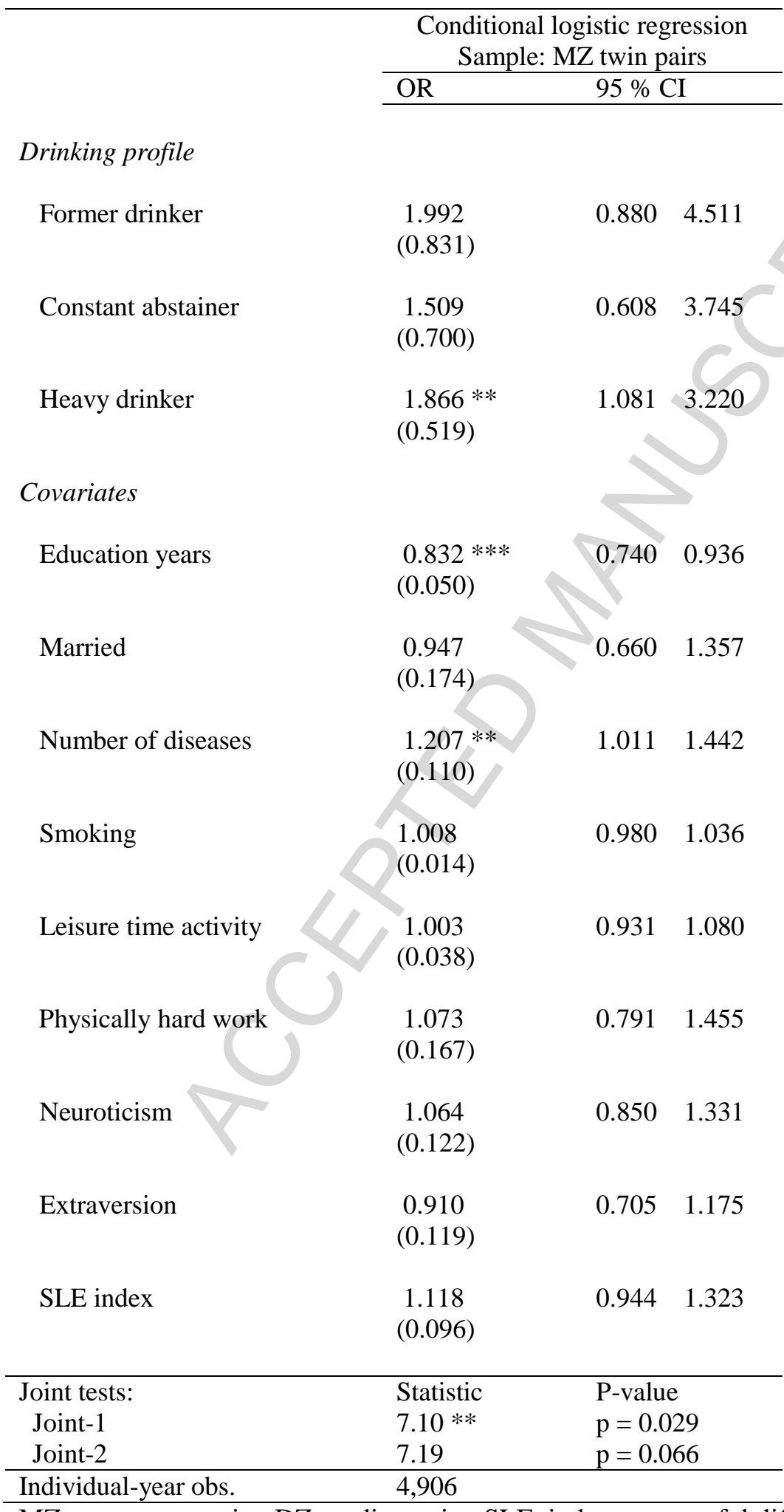

$\mathrm{MZ}=$ monozygotic $; \mathrm{DZ}=$ dizygotic $;$ SLE index = stressful life events index. Heteroscedasticity-robust standard errors in parentheses. Reference category: Moderate drinkers. Statistical significance: $* * *(\mathrm{p}<0.01)$, and $* *(\mathrm{p}<0.05)$. Joint- 1 is a joint test of the significance of the OR estimates of the heavy and former 
drinkers. Joint-2 is a joint test of the significance of the OR estimates of the heavy and former drinkers and constant abstainers. 


\section{Highlights}

Alcohol consumption is a potential determinant of receiving a disability pension.

We use twin data to account for family and genetic factors shared by identical twins.

Heavy drinkers are substantially more likely to receive a disability pension.

Drinking profiles are an important predictor of receiving a disability pension. 